\title{
Removal of a migrated biliary stent using new digital cholangioscopy retrieval devices in a transplant patient
}

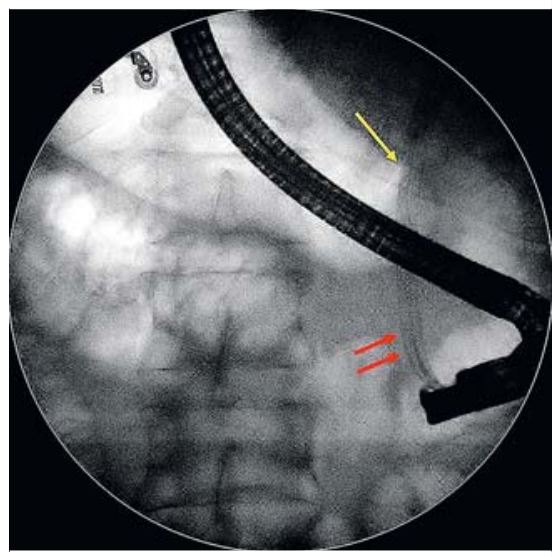

- Fig. 1 Fluoroscopy image during an endoscopic retrograde cholangiopancreatography plastic stent exchange session showing that one 8.5 -Fr plastic stent has migrated proximally (yellow arrow), while the other two plastic stents remain well positioned (red arrows).

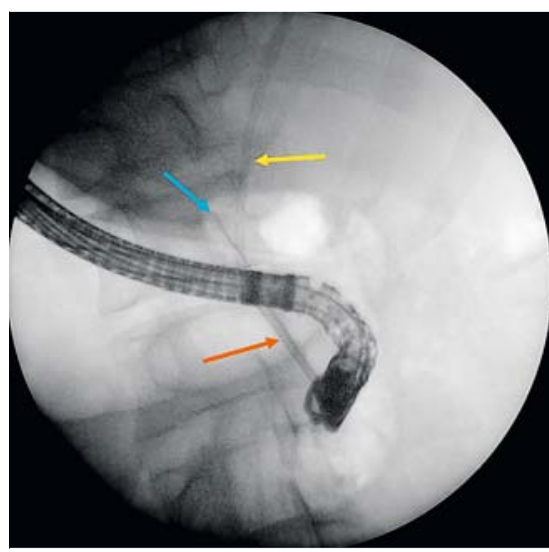

- Fig. 3 Fluoroscopy image showing the intraductal cholangioscope (SpyScope DS; orange arrow) and the new retrieval snare (SpySnare; blue arrow) wrapping around the proximally migrated plastic stent (yellow arrow).

A 51-year-old man who had undergone liver transplantation developed a symptomatic anastomotic biliary stricture 23 months after surgery. Endoscopic biliary therapy via endoscopic retrograde cholangiopancreatography (ERCP) was planned. Progressive biliary balloon dilation

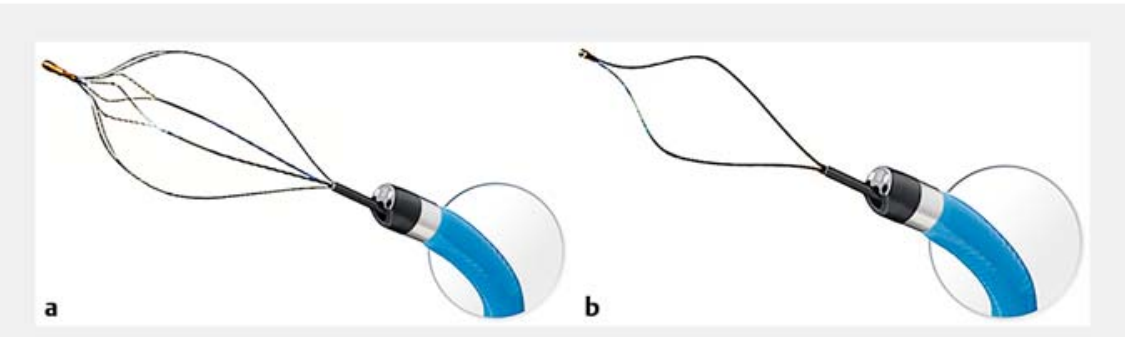

Fig. 2 The new intraductal cholangioscopy retrieval devices: a the basket (SpyBasket); b the snare (SpySnare). Source: Boston Scientific.

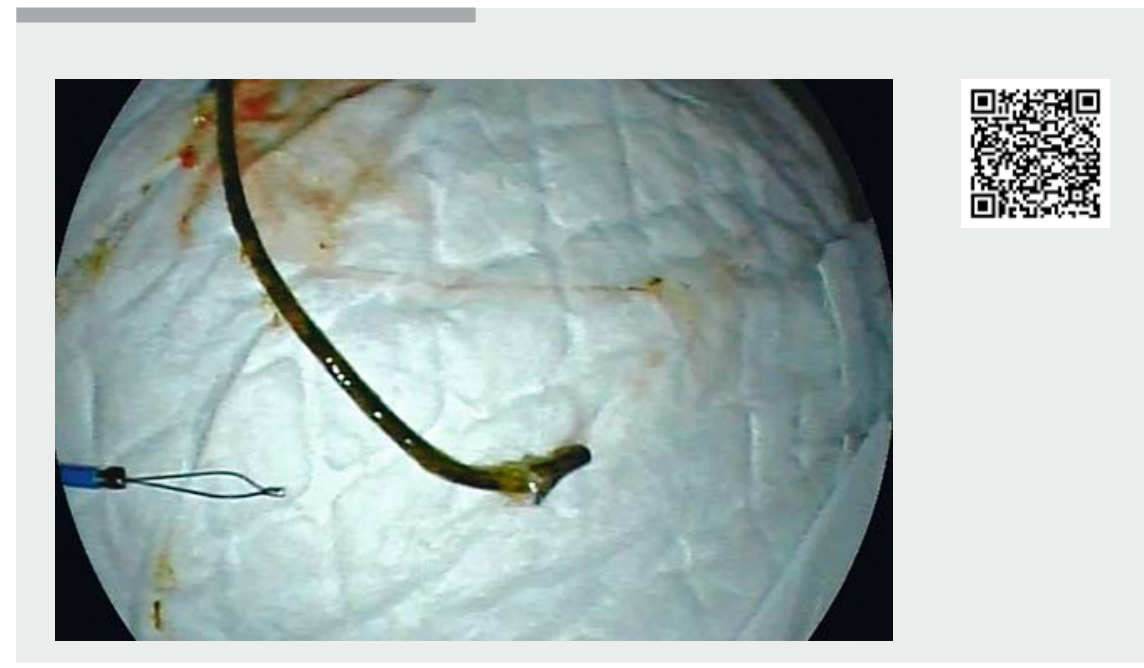

Video 1 Successful disimpaction and removal of a proximally migrated plastic stent using new retrieval devices for single-operator peroral cholangioscopy (SpyBasket and SpySnare) in a patient who had undergone liver transplantation. Source for stents: Boston Scientific.

of the stenosis was performed, with placement of three coaxial plastic stents (8.5- $\mathrm{Fr} \times 12 \mathrm{~cm}, 8.5-\mathrm{Fr} \times 9 \mathrm{~cm}$, and $10-\mathrm{Fr} \times$ $12 \mathrm{~cm}$; Advanix, Boston Scientific, Natick, Massachusetts, USA).

During an endoscopy to replace the stents, fluoroscopy revealed proximal migration of an 8.5- $\mathrm{Fr}$ plastic stent at the level of the cystic insertion ( $\triangleright$ Fig. 1). Several failed extraction attempts were made using the standard ERCP techniques (i. e. extractor balloon, Lasso technique, and others) [1,2]. Single-operator peroral intraductal cholangioscopy (Spy-
Glass DS direct visualization system, Boston Scientific) confirmed impaction of the distal end of the proximally migrated stent, located $3 \mathrm{~cm}$ proximally to the duodenal papilla. An attempt to mobilize the migrated stent was made using biopsy forceps (SpyBite, Boston Scientific), without success.

Finally, use of the new intraductal cholangioscopy retrieval devices (basket and snare) ( $\triangleright$ Fig. 2) allowed successful stent removal. Firstly, the stent was disimpacted using the new SpyBasket (Boston Scientific), then the distal end was wrapped 
by the SpySnare (Boston Scientific) ( $>$ Fig.3), and the migrated stent was totally extracted ( $\nabla$ Video 1 ).

Proximal migration of biliary stents occurs in around $5 \%$ of ERCP procedures, despite the antimigratory design of the stents [3]. Although in most cases extraction is possible, it may be challenging and technically difficult. Sporadically, the use of single-operator cholangioscopy and biopsy forceps has been reported [4].

This is the first case to report the use of the new intraductal cholangioscopy retrieval devices for the removal of a migrated plastic stent. The appearance of these dedicated tools expands the therapeutic armamentarium in the biliary tract and pancreatic duct and allows for single-operator peroral cholangiopancreatoscopy.

Endoscopy_UCTN_Code_TTT_1AR_2AZ

Competing interests

None
The authors

Francesc Bas-Cutrina' ${ }^{1}$, Albert Garcia-

Sumalla ${ }^{1}$, Julio Velasquez ${ }^{1}$, Claudia F.

Consiglieri ${ }^{1}$, Laura Lladó ${ }^{2}$, Joan B. Gornals ${ }^{1,3}$

1 Endoscopy Unit, Department of Digestive Diseases, Hospital Universitari de BellvitgeIDIBELL, University of Barcelona, Catalonia, Spain

2 Liver Transplant Unit, Department of Surgery, Hospital Universitari de BellvitgeIDIBELL, University of Barcelona, Catalonia, Spain

3 Faculty of Health Sciences, Universitat Oberta de Catalunya, Barcelona, Catalonia, Spain

\section{Corresponding author}

\section{Joan B. Gornals MD, PhD}

Endoscopy Unit, Dept. of Digestive Diseases, Hospital Universitari de Bellvitge-IDIBELL (Bellvitge Biomedical Research Institute), Feixa Llarga s/n, 08907 L'Hospitalet de Llobregat, Barcelona, Catalonia, Spain Fax: +34-93-2607681

jgornals@bellvitgehospital.cat

\section{References}

[1] Tarnasky PR, Cotton PB, Baillie J et al. Proximal migration of biliary stents: attempted endoscopic retrieval in forty-one patients. Gastrointest Endosc 1995; 42: 513 - 520

[2] Chaurasia OP, Rauws EA, Fockens P et al. Endoscopic techniques for retrieval of proxi- mally migrated biliary stents: the Amsterdam experience. Gastrointest Endosc 1999; 50: $780-785$

[3] Okabe Y, Tsuruta O, Kaji R et al. Endoscopic retrieval of migrated plastic stent into bile duct or pancreatic pseudocyst. Dig Endosc 2009; 21: 1-7

[4] Ogura T, Okuda A, Miyano A etal. Migrated endoclip removal after cholecystectomy under digital single-operatorcholangioscopy guidance. Endoscopy 2018; 50: 74-75

\section{Bibliography}

DOI https://doi.org/10.1055/a-0916-8490

Published online: 4.6.2019

Endoscopy 2019; 51: E323-E324

(c) Georg Thieme Verlag KG

Stuttgart · New York

ISSN 0013-726X

\section{ENDOSCOPY E-VIDEOS}

https:/|eref.thieme.de/e-videos

回局 Endoscopy E-Videos is a free

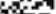
Fin access online section, reporting 回: on interesting cases and new techniques in gastroenterological endoscopy. All papers include a high quality video and all contributions are freely accessible online.

This section has its own submission website at https://mc.manuscriptcentral.com/e-videos 